\title{
Correspondence
}

\section{Dynamic compliance in preterm ventilated babies}

Sir,

We read with interest the recent paper of Thomson et al, ${ }^{1}$ especially as their experience was at such variance with our own. We too have been aware of the necessity of determining the accuracy of the measurement of dynamic compliance in sick, ventilated babies and have recently studied this by comparing dynamic and static compliance. Dynamic compliance was measured on 116 different occasions during a temporary disconnection from the ventilator, using a different system with an oesophageal balloon and single pneumotachograph placed in the endotracheal tube. Static compliance was measured using the positive pressure applied by the ventilator for $0.5 \mathrm{sec}$ (pressure measured from the endotracheal tube) and the resultant volume change measured by the same pneumotachograph. Expiratory volumes were used for both measurements. The results were calculated from an average of 10 breaths. All the pressure transducers had identical response times.

Using this system we found poor agreement between oesophageal and airway pressure during attempted airways occlusion by obstruction of the endotracheal tube; this was because complete occlusion was not possible as there was usually a leak around the uncuffed endotracheal tube. On $25 \%$ of occasions it was not possible to achieve an accurate static compliance because the infants actively expired against the applied pressure. When these infants were paralysed, however, an accurate static compliance measurement could be made and this correlated well with the dynamic compliance measurement immediately before paralysis. In infants for whom we were able to make an accurate static compliance measurement, this correlated well with dynamic compliance on 78 occasions $(r=0.94)$.

In our early studies dynamic compliance was inaccurate on $11 \%$ of occasions due to under recording of the oesophageal balloon, but with improvement in balloon production and user technique we have been able to reduce this to $2 \%$. In those infants whose condition remained stable we also found the measurement of dynamic compliance highly reproducible $(r=1 \cdot 0)$ over periods of up to five hours.

In summary, we have found dynamic compliance measurements in ventilated babies to be both accurate and reliable. Neither static nor total respiratory system compliance measurements could be made accurately, however, when the infants were actively expiring against the ventilator or there was a leak around the endotracheal tube.

Thomson et al conclude in their study that dynamic compliance is inaccurate in ventilated babies because of malrecording of the oesophageal ballons. The discrepancy in their study could, however, have been caused by faulty volume recording, as dynamic compliance correlated well with total respiratory system compliance in the healthy babies when exactly the same volume recording apparatus was used. In the ventilated babies, however, they used a new and relatively complex method of volume measurement in which one pneumotachograph measured the constant flow through the ventilator tubing (about 10 $\mathrm{V} / \mathrm{min}$ ) and a second pneumotachograph measured the biased flow plus the tidal flow. By electronically comparing the two signals the tidal volume was calculated. We would need more information to be convinced of the accuracy of this system.

Although Thomson et al comment that total respiratory system compliance may be a useful measurement for clinical purposes, for the reasons we have stated above its use would be severely limited. The two examples they gave of changes in this over the first days of life show consistent improvement in lung function with age. This is rather surprising, as both our own measurements and clinical parameters show that many babies with respiratory distress syndrome deteriorate over the first few days before improving, as is shown by the trends in dynamic compliance in 'infant 1 ' of their paper. ${ }^{1}$

\section{Reference \\ 1 Thomson, A, Elliot J, Silverman M. Pulmonary compliance in sick low birthweight infants. Arch Dis Child 1983;58:891-6. \\ A Greenough and C J Morley Department of Paediatrics, University of Cambridge, Addenbrooke's Hospital, Hills Road, Cambridge CB2 $2 Q Q$}

\section{Drs Thomson and Silverman comment:}

With only sketchy details it would be improper of us to comment on the techniques of Greenough and Morley. We find it surprising, however, that they made any measurements of lung function at all, when there was "usually a leak around the endotracheal tube'. To obtain perfect reproducibility over five hour intervals in sick preterm babies is, under these circumstances, truly remarkable.

The questions which have been raised about our system for measuring tidal volume in ventilated babies were answered in the original paper. Since we used the same system for the measurement of static and dynamic compliance errors in tidal volume, measurement would have been common to both and could not explain any difference. This was the basis of our conclusion that the error lay in the measurement of pressure and not volume. 
Doubt is being cast increasingly on the validity of oesophageal pressure measurements in sick infants. Indeed, even in the absence of lung disease extreme prematurity itself can sometimes render such measurements inaccurate. Without accurate and reproducible measurements of oesophageal pressure, dynamic compliance cannot be reliably measured in these groups of infants.

\section{Phototherapy for neonatal hyperbilirubinaemia}

Sir,

Drs Modi and Keay' conclude that phototherapy without measurement of irradiance is incomplete and inefficient. They would presumably like to see all neonatal units equipped with a radiometer. At a cost of $£ 300$ each and assuming one radiometer per 2000 births, this would cost the country approximately $£ 100000$. They have treated well, term babies who had no haemolysis but do not address the question of whether such babies need phototherapy, or indeed any therapy at all. ${ }^{2}$ Haven't the horse and the cart exchanged positions somewhere along the line? Unnecessary efficiency is inefficient efficiency and it has yet to be shown that babies with physiological jaundice benefit from being removed from their mothers and placed under a light with their eyes covered.

D P ADDY

Department of Paediatrics, Dudley Road Hospital, Birmingham $\mathrm{B} 187 \mathrm{QH}$

Drs Modi and Keay comment:

Dr Addy mistakes the point. Our study addressed itself to the question of whether the effectiveness of phototherapy, as currently used, might be improved. ${ }^{1}$ We did not, as he so rightly points out, question whether healthy babies with physiological jaundice require treatment at all.

A reasonable inference from our finding that phototherapy is used badly in well babies is that it is also used badly when its effectiveness is critical-in sick, preterm babies and in rhesus haemolytic disease.

We are also among those who believe that phototherapy is frequently used unnecessarily. While the question of treatment in well, term babies is debated, however, we feel any treatment considered necessary should be effective. We do not suggest that every neonatal unit in the country be equipped with a radiometer; we do, however, suggest that units providing intensive care are. We further suggest that manufacturers of phototherapy units provide irradiance specifications and that paediatricians appreciate that better use may be made of existing units.

\section{References \\ ' Modi N, Keay AJ. Phototherapy for neonatal hyper- bilirubinaemia: the importance of dose. Arch Dis Child 1983;58:406-9. \\ 2 Watchko JF, Oski FA. Bilirubin $20 \mathrm{mgm} / \mathrm{dL}=$ Vigintiphobia. Pediatrics 1983:71:660-3.}

\section{Fibrin stabilising factor in Schönlein-Henoch syndrome}

Sir,

We read with interest the article by Dalens et al ${ }^{1}$ which supports our own data. ${ }^{2}$ In a similar study we showed that some patients have low activity of fibrin stabilising factor in the acute phase of Schönlein-Henoch purpura. Determination of the fibrin stabilising factor in the early stage of Schönlein-Henoch purpura seems to be useful in the prognosis and management of patients, especially those with nephritis. The authors have stated in the summary that an increase in fibrin stabilising factor is associated with recovery. We believe, however, that this is not true in patients with Schönlein-Henoch purpura nephritis. Our results suggest that it is possible for the nephritis to progress after fibrin stabilising factor values return to normal and because of this, patients with a low fibrin stabilising factor value in the acute phase of disease deserve close follow up even if they show a later increase.

\section{References}

1 Dalens B, Travade P, Labbé A, Bezou MJ. Diagnostic and prognostic value of fibrin stabilising factor in Schönlein-Henoch syndrome. Arch Dis Child 1983;58:12-4.

2 Yoshioka K, Miyata H, Maki S. Significance of decreased factor XIII in Schönlein-Henoch purpura. Acta Paediatrica Japonica 1980;22:51-5.

Kazuo Yoshioka Department of Pediatrics, Kinki University School of Medicine, Sayama, Minamikawachi, Osaka 589, Japan 